\title{
The Early Psychosis Intervention Center (EPICENTER): development and six-month outcomes of an American first-episode psychosis clinical service
}

Nicholas J. K. Breitborde ${ }^{1,2^{*}}$, Emily K. Bell ${ }^{2}$, David Dawley ${ }^{2}$, Cindy Woolverton ${ }^{3}$, Alan Ceaser ${ }^{2,4}$, Allison C. Waters ${ }^{2,5}$, Spencer C. Dawson ${ }^{3}$, Andrew W. Bismark ${ }^{6}$, Angelina J. Polsinelli ${ }^{3}$, Lisa Bartolomeo ${ }^{2}$, Jessica Simmons ${ }^{7}$, Beth Bernstein ${ }^{2}$ and Patricia Harrison-Monroe ${ }^{2}$

\begin{abstract}
Background: There is growing evidence that specialized clinical services targeted toward individuals early in the course of a psychotic illness may be effective in reducing both the clinical and economic burden associated with these illnesses. Unfortunately, the United States has lagged behind other countries in the delivery of specialized, multi-component care to individuals early in the course of a psychotic illness. A key factor contributing to this lag is the limited available data demonstrating the clinical benefits and cost-effectiveness of early intervention for psychosis among individuals served by the American mental health system. Thus, the goal of this study is to present clinical and cost outcome data with regard to a first-episode psychosis treatment center within the American mental health system: the Early Psychosis Intervention Center (EPICENTER).

Methods: Sixty-eight consecutively enrolled individuals with first-episode psychosis completed assessments of symptomatology, social functioning, educational/vocational functioning, cognitive functioning, substance use, and service utilization upon enrollment in EPICENTER and after 6 months of EPICENTER care. All participants were provided with access to a multi-component treatment package comprised of cognitive behavioral therapy, family psychoeducation, and metacognitive remediation.
\end{abstract}

Results: Over the first 6 months of EPICENTER care, participants experienced improvements in symptomatology, social functioning, educational/vocational functioning, cognitive functioning, and substance abuse. The average cost of care during the first 6 months of EPICENTER participation was lower than the average cost during the 6-months prior to joining EPICENTER. These savings occurred despite the additional costs associated with the receipt of EPICENTER care and were driven primarily by reductions in the utilization of inpatient psychiatric services and contacts with the legal system.

Conclusions: The results of our study suggest that multi-component interventions for first-episode psychosis provided in the US mental health system may be both clinically-beneficial and cost-effective. Although additional research is needed, these findings provide preliminary support for the growing delivery of specialized multi-component interventions for first-episode psychosis within the United States.

(Continued on next page)

\footnotetext{
* Correspondence: Nicholas.Breitborde@osumc.edu

'Department of Psychiatry and Behavioral Health, The Ohio State University, Columbus, Ohio, USA

${ }^{2}$ Department of Psychiatry, The University of Arizona, Tucson, Arizona, USA

Full list of author information is available at the end of the article
}

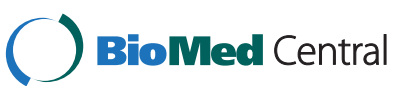

(C) 2015 Breitborde et al. Open Access This article is distributed under the terms of the Creative Commons Attribution 4.0 International License (http://creativecommons.org/licenses/by/4.0/), which permits unrestricted use, distribution, and reproduction in any medium, provided you give appropriate credit to the original author(s) and the source, provide a link to the Creative Commons license, and indicate if changes were made. The Creative Commons Public Domain Dedication waiver (http://creativecommons.org/publicdomain/zero/1.0/) applies to the data made available in this article, unless otherwise stated. 
(Continued from previous page)

Trial registration: ClinicalTrials.gov Identifier: NCT01570972; Date of Trial Registration: November 7, 2011

Keywords: First-episode psychosis, Treatment, Cognitive behavioral therapy, Family psychoeducation, Cognitive remediation, Cost-effectiveness

\section{Background}

Psychotic disorders exert a significant burden under current systems of care worldwide. Despite advances in the treatment of these disorders, individuals with psychosis typically experience a course of illness characterized by repeated relapses of psychotic symptoms [1], persistent unemployment [2], limited social relationships [3], and premature mortality [4]. Not surprisingly, the cost of care for psychotic disorders is astronomical. For example, within the United States, the cost of care in 2002 for a single psychotic disorder (i.e., schizophrenia) was nearly 63 billion dollars [5], suggesting that in 2015 the cost will exceed $\$ 81$ billion dollars after adjusting for inflation [6].

There is growing evidence that specialized clinical services targeted toward individuals early in the course of a psychotic illness may be effective in reducing both the clinical and economic burden associated with these illnesses [7-11]. The success of these early intervention services has sparked significant health services reform worldwide, including the establishment of a national early intervention service network in the United Kingdom [12] and the funding of a similar national care system by the federal government of Australia [13].

Unfortunately, the United States has lagged behind other countries in the delivery of specialized, multicomponent care to individuals early in the course of a psychotic illness [14]. A key factor contributing to this lag is the limited available data demonstrating the clinical benefits and cost-effectiveness of early intervention for psychosis among individuals served by the American mental health system $([14,15]$, however, see $[11,16,17])$. Consequently, there is a clear need for additional systematic evaluations of multi-component treatment packages for individuals with first-episode psychosis in the United States.

Thus, the goal of this manuscript is twofold. First, we will review the process of developing a multi-component treatment program for individuals with first-episode psychosis within the American mental health system: the Early Psychosis Intervention Center (EPICENTER: [18, 19]). Established in 2010 within the Department of Psychiatry at the University of Arizona, this program serves a catchment area of approximately 1 million individuals in the southwest United States. Second, we will review clinical and cost data among EPICENTER participants during the 6 months prior to joining EPICENTER as compared to during the first 6 months of EPICENTER care. The purpose of this activity is to quantify the possible clinical and economic benefits associated with EPICENTER participation.

\section{Methods}

Human subject research completed as part of this project was approved by the University of Arizona Institutional Review Board (Project Numbers 09-1113-02 and 10-0440-02) and was completed in compliance with the Helsinki Declaration.

\section{Participants}

Participants in this study were the first 68 individuals with first-episode psychosis consecutively enrolled at EPICENTER. Eligibility criteria for EPICENTER include: diagnosis of a schizophrenia-spectrum disorder or affective disorder with psychotic features as determined using the Structured Clinical Interview for the DSM-IV-TR [20]; onset of psychotic symptoms within the past 5 years per the Symptom Onset in Schizophrenia Inventory [21]; ages 15-35; and no evidence of mental retardation or organic brain impairment as evidenced by a premorbid IQ greater than 70 as estimated using the Reading subtest of the Wide Range Achievement Test [22]. Among the current sample, there were 49 men and 19 women with an average age of 22.71 years. The median duration of time since the onset of psychotic symptoms was 16.76 months. The distribution of psychotic disorder diagnoses is summarized in Fig. 1. Seventyeight percent were prescribed antipsychotic medication prior to enrollment in EPICENTER, and none had previously participated in evidence-based psychosocial treatment for psychosis.

During the time in which these 68 individuals were consecutively enrolled in EPICENTER, a total of 264 individuals were referred to this clinical service. Fortyseven of these referred individuals were excluded from participation due to being younger than 15 years $(n=$ 17), not having psychosis $(n=12)$, having a first onset of psychotic symptoms $>5$ years prior $(n=10)$, being older than 35 years $(n=4)$, having an estimated premorbid IQ $<70(n=2)$, having psychosis resulting from a general medical condition $(n=1)$, and having attenuated psychotic symptoms that did not meet DSM-IV criteria for a psychotic disorder $(n=1)$. An additional 149 were referred to the study but declined to participate in the eligibility assessment. 


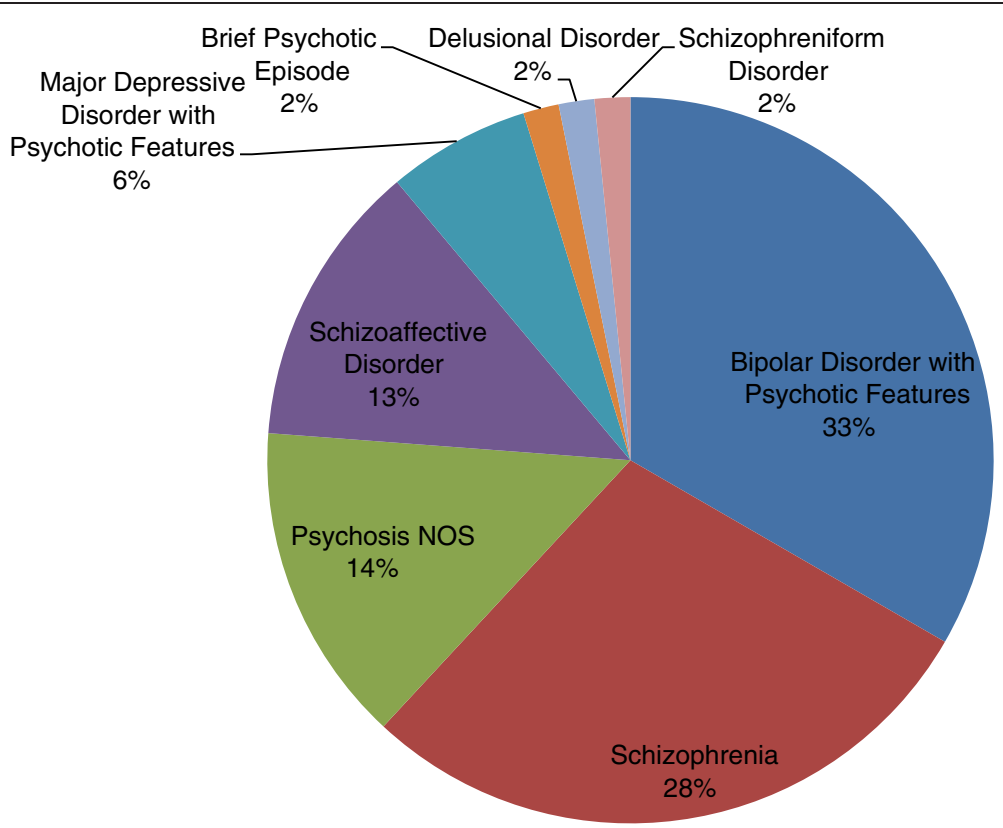

Fig. 1 Distribution of Psychotic Disorder Diagnoses among EPICENTER Participants

Written informed consent with regard to study participation was obtained from all adult subjects. For participants under the age of 18, written informed consent was obtained from the participant's parent or guardian and written assent was obtained from the participant.

\section{Procedures}

Individuals with first-episode psychosis completed the measures described below as part of a larger research battery designed to investigate mediators and moderators of treatment response among individuals with first-episode psychosis $[19,23]$. All measures were administered upon enrollment in EPICENTER and after 6 months of participation in EPICENTER services. When possible, assessments were administered by blinded researchers. However, in some instances, baseline assessments (i.e., assessments completed prior to the start of EPICENTER care) were completed by EPICENTER clinical staff due to staffing limitations.

\section{Measures}

\section{Symptomatology}

Severity of psychotic symptoms was assessed using the Positive and Negative Syndrome Scale (PANSS: [24]). The PANSS is a 30-item clinician-rated scale that assesses three domains of symptomatology: positive symptoms, negative symptoms, and general symptoms. Items are rated such that higher scores are indicative of worse symptomatology.

\section{Social and educational/vocational functioning}

The Social Functioning Scale (SFS: [25]) was used to measure social functioning among study participants. This 79- item questionnaire assesses six domains of social functioning: social engagement/withdrawal; interpersonal behavior/ communication; participation in prosocial activities; participation in recreational activities; independence-competence; and independence-performance. Each domain is scored such that higher scores are indicative of better functioning. A total social functioning score was calculated by summing all SFS subscales into a single variable.

The SFS also provides data with regard to participants' level of educational/vocational functioning on a $0-10$ scale ranging from no perceived capability to work and no active efforts to find a job (0) to participation in full time work/school (10). Consistent with past analyses of educational/vocational functioning among individuals with first-episode psychosis using the SFS [17], these scores were transformed into a dichotomous categorical variable defined as employed/in school (i.e., part-time or greater participation in competitive work/school) versus unemployed/not in school.

\section{Cognitive functioning}

The MATRICS Consensus Cognitive Battery (MCCB: [26]) was utilized to assess cognitive functioning among study participants. This battery assesses seven domains of cognitive functioning: (i) processing speed; (ii) attention/vigilance; (iii) working memory; (iv) verbal learning; (v) visual learning; (vi) reasoning and problem-solving; and (vii) social cognition. An overall index of cognitive functioning is also computed. Scores are reported as Tscores with higher scores indicative of greater cognitive functioning. The MATRICS offers alternate versions of 
tests used to assess verbal learning and reasoning and problem-solving to reduce the effect of practice on results from trials in which these measures are administered multiple times. We utilized these alternate forms in the current study and the order in which original and alternate forms were administered was counterbalanced across participants.

\section{Substance use}

The severity of participants' substance use was assessed using the Alcohol Use Scale/Drug Use Scale (AUS/DUS: [27]). The AUS/DUS is a clinician-rated scale that assesses use of 12 substances: tobacco, alcohol, marijuana/THC, cocaine, opiates, phencyclidine (PCP), amphetamines, 3,4methylenedioxy- $N$-methylamphetamine (MDMA), gamahydroxy butarate (GHB) or flunitrazepam (Rohypnol), huffing of glue or other volatiles, hallucinogens, and other substances of abuse not otherwise specified. Severity of participants' use is rated on a 5-point scale based on DSM-IV-TR criteria for severity of use: (1) abstinent; (2) use without impairment; (3) abuse; (4) dependence; and (5) dependence with institutionalization. Based on these ratings, participants' were assigned an overall substance use score using the same 5-point scale. This overall score was calculated as the highest severity ranking earned by a participant across all 12 substance categories.

\section{Service utilization and cost-effectiveness}

The Service Utilization and Resources Form for Schizophrenia (SURF: [28]) was used to assess participants' utilization of psychiatric and legal resources. With regard to psychiatric resources, we tracked participants' use of EPICENTER services as well as non-EPICENTER outpatient mental health services that participants may have chosen to utilize during study participation (e.g., case management, medication management, etc.). Cost outcomes for EPICENTER participants were calculated using cost estimates associated with inpatient hospitalization in Arizona [29] and contact with the legal system [30]. Data with regard to financial support provided by family members was assessed directly in the SURF. Costs associated with unemployment and non-participation in competitive education among young adults were obtained from a recent report from the Corporation for National and Community Service and the White House Council for Community Solutions [31] and included costs associated with lost wages, poor health, and contact with the legal system as well as savings associated with reduced use of government subsidies designed to support participation in higher education. Given that we already obtained estimates of costs associated with contact with the legal system elsewhere, these costs were not included when calculating the total costs associated with unemployment and non-participation in competitive education.
Antipsychotic medication use was assessed using the current medication form-a measure used in past studies of first-episode psychosis [32, 33]. Antipsychotic medications were converted to chlorpromazine equivalents using the conversion values developed by Leucht and colleagues [34] and Woods [35]. Costs for antipsychotic medication used by EPICENTER participants were calculated using 2015 prices for non-generic antipsychotic medication.

Costs for EPICENTER services were calculated using salary and benefits cost data for EPICENTER clinical staff and indirect cost estimates from the hospital where the program is located. Similar to a previous cost-effectiveness evaluation of clinical services for first-episode psychosis [9], costs for non-EPICENTER outpatient mental health services were calculated by multiplying the number of such services by the hourly rate for a mental health counselor as reported in the 2013 National Occupational Employment and Wage Estimates for the United States [36]. Indirect costs for non-EPICENTER outpatient mental health services were calculated using the same indirect rates used for EPICENTER outpatient mental health services. All cost estimates were adjusted to 2015 values to correct for inflation.

\section{Multi-component intervention}

The components of the EPICENTER intervention package were selected following a series of meetings with mental health stakeholders in our local community. Stakeholders included administrators and practitioners in the public and private mental health systems, members of local advocacy groups, and individuals with a mental illness. In these meetings, stakeholders identified access to evidence-based psychosocial interventions as the key treatment need of individuals with first-episode psychosis in our community. Stakeholders verified that the need for psychiatric medication was successfully addressed by existing resources in our community. This information is consistent with existing data on access to evidence-based psychosocial interventions [37-39] and antipsychotic medication [37, 39] published by other research groups in the United States.

Thus, to avoid duplication of existing services, we limited the components of the EPICENTER multicomponent treatment package solely to evidence-based psychosocial interventions for psychosis that were otherwise unavailable in our community. All participants interested in receiving antipsychotic medication were able to do so through community providers not affiliated with the study. Selection of components of this treatment package was determined based on the a priori goals to (i) balance the need to address the psychiatric symptomatology and functional deficits (e.g., 
cognitive functioning deficits) that are part of the core pathology of psychotic disorders with the goal of providing the least time-intensive intervention package for individuals with psychosis $[40,41]$; (ii) incorporate interventions that could be applied with fidelity while simultaneously being flexible enough to be responsive to the varying needs of EPICENTER participants [42, 43]; (iii) address the unique gaps in treatment experienced by individuals with psychosis in our catchment area (i.e., limited access to evidence-based psychosocial interventions); and (iv) be delivered effectively given the available staffing resources which ranged from approximately 0.5 to 1.0 full-time positions during the course of the study. The resulting intervention package was comprised of three components: cognitive behavioral therapy, family psychoeducation, and cognitive remediation. Evidence from the study of each respective component suggests that this combined treatment package may address both the symptomatology [44-47] and functional deficits [48-50] common among individuals with psychotic disorders. To increase the flexibility of this intervention package, we selected interventions that could be delivered individually or in group format. Staffing limitations precluded the inclusion of certain evidence-based treatments (e.g., supported employment and education) for which a dedicated full-time staff member is recommended $[51,52]$.

Upon enrollment in EPICENTER, participants were provided with education with regard to the different elements of the multi-component intervention package. Participants were then allowed to choose which interventions they would complete during their care at EPICENTER.

\section{Cognitive Behavioral Therapy (CBT)}

CBT is an evidence-based treatment for individuals with psychotic disorders [53] with demonstrated efficacy in both individual [54] and group formats [55]. Of note, though, a recent meta-analysis published after the launch of EPICENTER has called into question the efficacy of this intervention for individuals with psychosis [56]. At EPICENTER we have opted to provide CBT in both an individual and group format. In both formats, we utilize well-established strategies for addressing the positive and negative symptoms that accompany psychotic disorders [57-59] as well as the other sequelae that accompany psychotic disorders, including anxiety [46], insomnia [60], post-traumatic stress disorder [61, 62], substance use [63], and deficits in social and vocational functioning [64-66]. The focus of the intervention is tailored to the specific needs and motivation of the individual with first-episode psychosis such that EPICENTER participants, in collaboration with their therapist, identify the specific therapeutic targets to address in CBT sessions.

\section{Family Psychoeducation (FP)}

Family psychoeducation is an evidence-based treatment for psychotic disorders [45]. The FP intervention utilized at EPICENTER [67] was based on the protocol developed by McFarlane and colleagues [45] and was modified to address the uniques strengths and challenges of individuals with first-episode psychosis. This intervention involves two modules: (i) joining, (ii) family problem-solving sessions. During the joining module, caregiving relatives meet individually with a clinician for one to three sessions to discuss the patient's clinical history, the family's experience and understanding of their relative's illness, and family members' concerns and questions with regard to participating in a multifamily group. Following the completion of the joining module, families and their ill relatives have the option to participate in regular family problem-solving sessions ( $2 \times$ per month). During the problem-solving sessions, caregivers and ill relatives identify challenges or problems occurring in their life and evaluate possible solutions to these problems through a structured problem-solving activity. Of note, the family problem-solving sessions, which are the primary component of this FP intervention, are delivered in either a multifamily group or single family format [68] depending on the preference of the family.

\section{Metacognitive Remediation (MCR)}

Cognitive remediation, which is recognized as a "best practice" in the treatment of psychotic disorders [69, 70], is typically comprised of a series of repeated exercises delivered by a clinician or via a computer that are designed to improve cognitive functioning.

At EPICENTER, participants received metacognitive remediation (MCR: [71, 72]) - a form of cognitive remediation shown to improve numerous domains of cognitive functioning among individuals with first-episode psychosis, including processing speed, attention/vigilance, working memory, verbal learning, visual learning, reasoning and problem-solving, and social cognition [71]. MCR involves participation in both computerized cognitive remediation exercises and metacognitive skills development exercises with a clinician. With regard to the former, participants were provided with the computerized CR program PSSCogRehab [73] - a program frequently used in past studies of cognitive remediation in psychotic disorders [74-80]. This program provides participants with training in four areas of cognitive functioning: cognitive foundations (e.g., attention and processing speed), visual-spatial abilities, memory, and problemsolving abilities. Participants initially complete simple tasks in each domain and, once mastered, gradually progress to more difficult tasks. Following each attempt to complete a PSSCogRehab exercise, individuals with firstepisode psychosis participate in a "metacognitive 
discussion" with a clinician designed to promote metacognitive skills development and facilitate transfer of knowledge/skills developed during the MCR session to real-world situations. Of note, not all EPICENTER participants were able to complete MCR during the first 6 months of EPICENTER care due to their participation in another study in which they were randomized not to receive this intervention during the first 6 months of care [81]. In addition, the first 10 EPICENTER participants to receive cognitive remediation did so before the development of MCR, and so completed the same PSSCogRehab tasks but did not participate in metacognitive discussions as described above.

\section{Statistical analyses}

All data were analyzed following the intention to treat principle [82]. Consistent with current statistical guidelines [83, 84], missing data were addressed using multiple imputation $[85,86]$. To facilitate the completion of these analyses, change scores were calculated for continuous variables by subtracting baseline assessment values from 6-month assessment values. These values were then analyzed using t-tests. For the investigation of within-subject change in categorical variables, $t$-values were calculated using effect sizes and standard errors combined using Rubin's rule [86, 87]. As degrees of freedom calculated using standard metrics for t-tests are overly liberal in the analysis of multiply imputed data, we adjusted the degrees of freedom for our analyses using the formula develop by Barnard and Rubin [88].

Participants who completed both the baseline and 6month assessments did not differ from those who only completed baseline assessments with regard to symptomatology, cognitive functioning, and most domains of substance use and social functioning. Individuals who did not complete the 6-month assessment reported higher use of marijuana and lower use of tobacco at baseline compared to individuals who completed both the baseline and 6-month assessment. Additionally, individuals who did not complete the 6 -month assessment reported better interpersonal communication and competence with regard to the completion of independent tasks of daily living as assessed by the SFS as compared to individuals who completed both the baseline and 6month assessment.

\section{Results}

\section{Intervention participation}

Rates of participation in EPICENTER interventions are summarized in Table 1. Among all interventions, individual CBT was the most utilized intervention with $61 \%$ of individuals with first-episode psychosis participating in this intervention. Individuals with first-episode psychosis were more likely to participate in individual CBT as
Table 1 Rates of participation in EPICENTER interventions

\begin{tabular}{ll}
\hline Intervention & Rate of Participation n(\%) \\
\hline Cognitive Behavioral Therapy_Individual & $47(61 \%)$ \\
Cognitive Behavioral Therapy_Group & $30(39 \%)$ \\
Family Psychoeducation_Individual & $17(22 \%)$ \\
Family Psychoeducation_Group & $34(44 \%)$ \\
Metacognitive Remediation & $19(25 \%)$ \\
\hline
\end{tabular}

compared to group CBT (39\%: $t=3.72 ; p<0.01$ ). Conversely, families were more likely to participate in multifamily (i.e., group) psychoeducation (44\%) as compared to individual family psychoeducation (22\%: $t=4.38 ; p<0.01)$.

\section{Symptomatology}

Baseline and 6-month follow-up scores for PANSS are presented in Table 2. Over the first 6 month of care, participants experienced reduction in both positive $(t=-3.93$; $p<0.01)$ and general symptoms $(t=-4.48 ; p<0.01)$. There

Table 2 Symptomatology, social functioning, cognition, and substance use at baseline and after 6 months of epicenter care

\begin{tabular}{lll}
\hline & Baseline & Six Months \\
\hline PANSS & & \\
1) Positive Symptoms & 15.53 & $13.03^{*}$ \\
2) Negative Symptoms & 15.07 & 13.52 \\
3) General Symptoms & 30.41 & $26.29^{*}$ \\
SFS & & \\
1) Social Engagement & 9.77 & 9.78 \\
2) Interpersonal Communication & 6.60 & 7.22 \\
3) Prosocial Activities & 15.44 & 18.77 \\
4) Recreation & 18.32 & 20.37 \\
5) Independence-Competence & 33.93 & $36.07^{*}$ \\
6) Independence-Performance & 22.85 & 25.47 \\
MCCB & & \\
1) Processing Speed & 35.39 & $41.29^{*}$ \\
2) Attention/Vigilance & 36.83 & 38.85 \\
3) Working Memory & 40.11 & 46.59 \\
4) Verbal Learning & 40.02 & $43.98^{*}$ \\
5) Visual Learning & 38.07 & 44.89 \\
6) Reasoning and Problem-Solving & 40.00 & 43.85 \\
7) Social Cognition & 42.33 & 49.86 \\
8) Overall Cognitive Composite & 32.9 & $40.16^{*}$ \\
AUS/DUS & & \\
1) Overall Substance Use & 2.53 & $1.95^{*}$ \\
2) Alcohol & 1.98 & $1.64^{*}$ \\
3) Marijuana & 1.76 & $1.39^{*}$ \\
4) Tobacco & 1.79 & 1.81 \\
\hline
\end{tabular}

${ }^{*} p<0.05$ as compared to value for baseline assessment 
was no change in severity of negative symptoms from baseline to 6 -month assessment $(t=-1.59 ; p=0.13)$.

\section{Social and educational/vocational functioning}

Baseline and 6-month follow-up scores for the SFS subscales are presented in Table 2. Overall, there was an increase in total social functioning over the first 6 months of EPICENTER care (total SFS $M=108.08$ vs. 118.92; $t=3.08 ; p=0.02$ ). With regard to SFS subscales, the independence-competence subscale increased over the first 6 months of EPICENTER care $(t=2.73 ; p=0.03)$, indicating that participants perceived themselves as more competent in the independent completion of tasks of daily living. There was no statistically significant change in any other SFS subscale from baseline to 6-month assessment.

Participation in competitive employment/education increased over the first 6 months of EPICENTER care. More specifically, the percentage of participants engaged in part-time or greater work/school increased from $38 \%$ at baseline to $49 \%$ after 6 months of EPICENTER care $(t=5.98 ; p<0.01)$.

\section{Cognitive functioning}

Baseline and 6-month follow-up scores for the MCCB are depicted in Table 2 . There was a statistically significant increase in the overall composite cognition score for individuals participating in EPICENTER care $(t=$ 3.14; $p=0.03)$. With regard to the individual MCCB subscales, there were statistically significant improvements in verbal learning $(t=2.54 ; p=0.01)$ and processing speed from baseline to 6-month assessment $(t=$ $5.05 ; p<0.01)$. There was also a trend suggesting possible improvements in visual learning from baseline to 6 -month assessment $(t=2.03 ; p=0.08)$. Of note, the magnitude of these improvements exceed changes that would be expected due to repeated administration of the MCCB alone (i.e., practice effects [89]).

\section{Substance use}

Baseline and 6-month follow-up scores for the AUS/ DUS are presented in Table 2. Participants' overall substance use declined from baseline to 6-month follow-up $(t=-5.55 ; p=0.01)$. Among our sample, the three most frequently used substances at baseline were alcohol (63\%), tobacco (53\%), and marijuana (48\%). Although participants' use of alcohol $(t=-2.34 ; p=0.03)$ and marijuana $(t=-3.16 ; p<0.01)$ both declined from baseline to 6-month assessment, there was no change in participants' use of tobacco during the first 6 months of EPICENTER care $(t=0.18 ; p=0.86)$.

\section{Service utilization and cost-effectiveness}

Service utilization for EPICENTER participants is summarized in Table 3. Individuals with first-episode psychosis participated in an average of 14.94 EPICENTER-related outpatient mental health visits during the first 6 months of EPICENTER care. The number of episodes of inpatient psychiatric hospitalization $(t=-3.29 ; p<0.01)$, nights of inpatient hospitalization $(t=-2.54 ; p=0.01)$, and contacts with the legal system $(t=-2.11 ; p<0.04)$ were lower in the first 6 months of EPICENTER care as compared to the 6 month period prior to the start of EPICENTER care. Conversely, there was a near significant increase in the number of non-EPICENTER outpatient mental health visits during the first 6 months of EPICENTER care $(t=2.18 ; p=0.07)$. Although antipsychotic medication dose declined from the baseline to 6-month assessment, this change did not meet criteria for statistical significance $(t=-0.99 ; p=0.34)$. Daily doses of antipsychotic medication (chlorpromazine equivalents) would be considered low (i.e., $\leq 400 \mathrm{mg}$ ) at baseline and after 6 months of EPICENTER care [90].

Per person cost of services are presented in Fig. 2. The cost of services received by individuals during the 6-month period prior to the start of EPICENTER care $(M=\$ 43,456)$ was greater than the cost of services during the first 6 months of EPICENTER care $(M=\$ 26,355$; $t=-3.00 ; p<0.01)$. Care elements contributing to this cost savings included reductions in costs associated with inpatient hospitalizations ( $\$ 27,480$ vs. $\$ 10,367 ; t=-3.24$; $p<0.01)$ and contact with the legal system $(\$ 8,604$ vs. $\$ 3,169 ; t=-2.10 ; p=0.04)$. There was a near significant increase in the costs associated with non-EPICENTER outpatient mental health services during the first 6 months of EPICENTER care ( $\$ 477$ vs. $\$ 854 ; t=2.16 ; p=$ $0.07)$. There was no change in costs associated with financial support provided by family members, cost of antipsychotic medications, or costs associated with being unemployed and not in school.

The per person cost of providing EPICENTER care to study participants was $\$ 6,136$. Dividing the difference of the total costs for the pre-EPICENTER and EPICENTER treatment periods $(\$ 17,101)$ by this value reveals that for every \$1 spent on EPICENTER care, $\$ 2.79$ dollars were saved during the first 6 months of treatment.

\section{Discussion}

The results of the current report highlight the potential clinical effectiveness of a multi-component psychosocial intervention package for first-episode psychosis. On average, individuals participating in EPICENTER care showed improvements in symptomatology, social functioning, educational/vocational functioning, cognitive functioning, and substance use during the first 6 months of treatment. These improvements occurred despite the fact that, on average, participants (i) were already taking antipsychotic medication prior to study enrollment and (ii) did not experience an increase in 
Table 3 Service utilization during 6-month period prior to epicenter care versus during first 6 months of epicenter care

\begin{tabular}{lll}
\hline & 6-Month Period Prior to EPICENTER Care & First 6 Months of EPICENTER Care \\
\hline Outpatient Mental Health Visits (Non-EPICENTER) & $M=14.59$ & $M=26.13$ \\
Outpatient Mental Health Visits (EPICENTER) & N/A & $M=14.94$ \\
Antipsychotic Medication (chlorpromazine equivalent) & $M=331.74 \mathrm{mg}$ & $M=288.72 \mathrm{mg}$ \\
Inpatient Hospitalization (Number of Episodes) & $M=0.88$ & $M=0.33^{*}$ \\
Inpatient Hospitalizations (Number of Days) & $M=13.18$ & $M=4.80^{*}$ \\
Contact with the Legal System (Number of Episodes) & $M=2.00$ & $M=0.73^{*}$ \\
\hline
\end{tabular}

${ }^{*} p<0.05$ as compared to value for 6 month period prior to EPICENTER care

antipsychotic medication dose during the course of the study. In total, these results add to the growing literature with regard the potency of psychosocial interventionsand multi-component psychosocial intervention packages-provided early in the course of a psychotic disorder $[45,91,92]$.

Yet, at the same time, care should be taken to avoid overly-enthusiastic views of the clinical benefits of the EPICENTER intervention package. Certain key outcomes among our participants (i.e., tobacco use and severity of negative symptoms) did not improve over the first 6-months of EPICENTER care. Likewise, although we found improvements in global measures of social and cognitive functioning among individuals with first-episode psychosis, analysis of the subcomponents of these global measures suggests a more conservative interpretation. For example, among the six subcomponents of social functioning used to calculate an overall score for the Social Functioning Scale, only one subscale increased significantly over the first 6 months of EPICENTER care (i.e., independence-competence). Likewise, only two of seven subcomponents used to calculate the overall cognitive functioning score for the MATRICS Consensus Cognitive Battery increased during the first 6 months of EPICENTER care (i.e., verbal learning and processing speed).
Moreover, with the exception of the social cognition subscale, performance on the remaining subscales remained 0.5-1.0 standard deviations below the norm for individuals without psychotic disorders (i.e., $T=50$ ) following 6 months of EPICENTER care. In total, these data highlight the need for continued investigations of intervention strategies with which to further improve clinical and functional outcomes among individuals with first-episode psychosis.

With regard to service utilization and cost of care, the data are more encouraging. More specifically, the average cost of care during the first 6 months of EPICENTER participation was lower than the average cost during the 6 months prior to joining EPICENTER. These savings occurred despite the additional costs associated with the receipt of EPICENTER care and were driven primarily by reductions in the utilization of inpatient psychiatric services and contacts with the legal system. These savings are especially valuable given the high cost of care of individuals with first-episode psychosis. More specifically, the per person 12-month cost of care among our sample of individuals with first-episode psychosis was $\$ 69,810-$ a cost value noticeably greater than that reported in other cost of care studies that did not limit their sample to individuals early in the course of their psychotic illness [5, 93, 94].

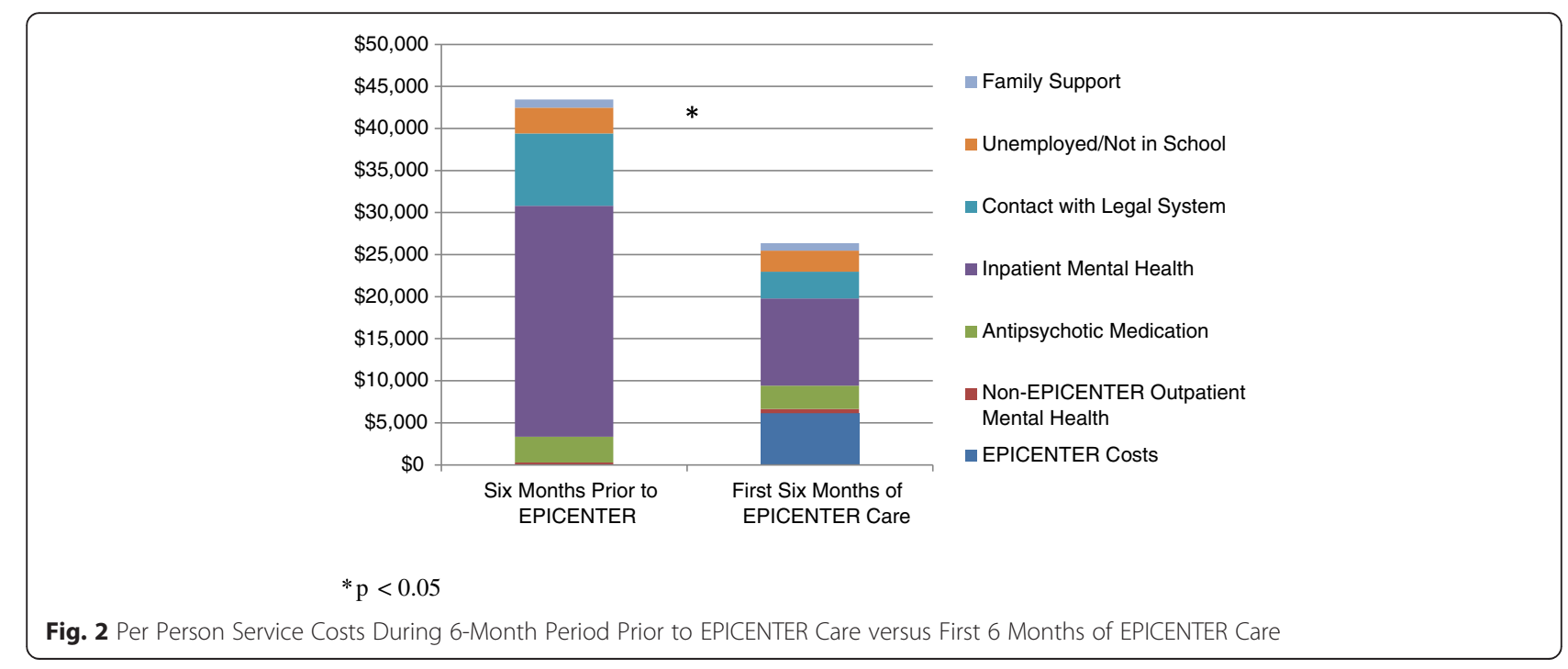


Despite the focus of the current investigation on psychosocial treatments, it is important not to overlook the importance of pharmacological interventions in the treatment of first-episode psychosis. The clinical benefits of such interventions are well documented in the psychosis literature [95]. As noted earlier, most participants were already taking antipsychotic medication prior to study enrollment, and the average per-participant dose of antipsychotic medication did not decline over the course of the study. Given the high rates of medication discontinuation/non-compliance reported in naturalistic studies of individuals with first-episode psychosis [96], the relative stability of medication dose among EPICENTER participants is particularly noteworthy and may have contributed to the positive clinical and cost outcomes among these individuals. Although not formally assessed, it may be that an unintended benefit of participation in EPICENTER care is the facilitation of greater medication adherence among study participants. This hypothesis comports with previous evidence that individuals participating in certain evidence-based psychosocial interventions for psychosis may display very high levels of medication adherence (e.g., multifamily group psychoeducation [68]). Ultimately, future studies are needed to more clearly unpack the association between participation in multi-component psychosocial treatment packages and adherence to pharmacological interventions among individuals with first-episode psychosis.

It is important to note that this study did suffer from a number of limitations-most notably the lack of a study design in which participants were randomly assigned to EPICENTER care versus usual care for first-episode psychosis in our community. With our current study design, it is impossible to rule out the possibility that the improvement in clinical outcomes and cost of care for individuals with first-episode psychosis may simply reflect the natural course of psychotic disorders and are not a result of participation in EPICENTER care. It seems unlikely, though, that this could completely account for our findings given the overwhelming evidence that many of the outcomes investigated in this study (e.g., cognition, social functioning, and educational/vocational functioning) typically worsen or remain stable over the early natural course of psychotic disorders [97-100].

\section{Conclusions}

The results of our study suggest that multi-component psychosocial interventions for first-episode psychosis provided in the US mental health system may be both clinically-beneficial and cost-effective. Although additional research is needed, these findings provide preliminary support for the growing delivery of specialized multi-component interventions for first-episode psychosis within the United States.

\section{Abbreviations}

AUS/DUS: Alcohol Use Scale/Drug Use Scale; CBT: Cognitive Behavioral Therapy; DSM-IV-TR: Siagnostic and Statistical Manual IV-Text Revised; EPICENTER: Early Psychosis Intervention Center; FP: Family Psychoeducation; IQ: Intelligence Quotient; MCCB: MATRICS Consensus Cognitive battery; MCR: Metacognitive Remediation; PANSS: Positive and Negative Syndrome Scale; SFS: Social Functioning Scale; SURF: Service Utilization and Resources form for Schizophrenia.

\section{Competing interests}

NJKB received research support from the Institute for Mental Health Research - an agency currently exploring the possibility of launching a multi-component treatment center for first-episode psychosis. The remaining authors declare that they have no competing interests.

\section{Authors' contributions}

NJKB designed the study, developed study intervention protocols, completed the analyses, and wrote the first draft of the manuscript. NJKB, EB, AC, ACW, SCD, $A B, A J P, B B$, and PH-M contributed to the delivery of study interventions. NJKB, $E B, D D, C W, A C, A C W, S C D, A B, L B$, and JS contributed to the administration and scoring of study assessments as well as data management. All authors provided critical revisions to manuscript and approve the final manuscript.

\section{Acknowledgements}

We would like to thank the individuals who participated in this study. Funding for this study was provided to NJKB by the University of Arizona Department of Psychiatry, the Institute for Mental Health Research, the Arizona Center for the Biology of Complex Diseases, the University of Arizona Vice President for Research, and a community donor who wishes to remain anonymous. Funding for the open-access publishing of this manuscript was provided by the University of Arizona Open Access Publishing Fund. None of the funding bodies played a role in the study design or the collection, analysis, and interpretation of the data, or in the writing of the manuscript.

\section{Author details}

${ }^{1}$ Department of Psychiatry and Behavioral Health, The Ohio State University, Columbus, Ohio, USA. '2Department of Psychiatry, The University of Arizona, Tucson, Arizona, USA. ${ }^{3}$ Department of Psychology, The University of Arizona, Tucson, Arizona, USA. ${ }^{4}$ Department of Psychiatry and Behavioral Sciences, Stanford University, Stanford, California, USA. ${ }^{5}$ Department of Psychiatry and Behavioral Sciences, Emory University School of Medicine, Atlanta, Georgia, USA. ${ }^{6}$ VISN-22 Mental IIIness, Research, Education and Clinical Center (MIRECC), VA San Diego Healthcare System, San Diego, California, USA. 'Department of Education, The University of Arizona, Tucson, Arizona, USA.

Received: 1 April 2015 Accepted: 14 October 2015

Published online: 28 October 2015

\section{References}

1. Hegarty JD, Baldessarini RJ, Tohen M, Waternaux C, Oepen G. One hundred years of schizophrenia: A meta-analysis of the outcome literature. Am J Psychiatr. 1994;151(10):1409-16.

2. Marwaha S, Johnson S. Schizophrenia and employment - a review. Soc Psychiatry Psychiatr Epidemiol. 2004;39(5):337-49.

3. Bengtsson-Tops A, Hansson L. Quantitative and qualitative aspects of the social network in schizophrenic patients living in the community. Relationship to sociodemographic characteristics and clinical factors and subjective quality of life. Int J Soc Psychiatry. 2001;47(3):67-77.

4. Brown S. Excess mortality of schizophrenia. A meta-analysis. Br J Psychiatry Suppl. 1997;171:502-8

5. Wu EQ, Birnbaum HG, Shi L, Ball DE, Kessler RC, Moulis M, et al. The economic burden of schizophrenia in the United States in 2002 J Clin Psychiatry. 2005;66:1122-9.

6. Consumer Price Index Inflation Calculator [http://www.bls.gov/data/ inflation_calculator.htm]

7. Mihalopoulos C, Harris M, Henry L, Harrigan S, McGorry P. Is early intervention in psychosis cost-effective over the long term? Schizophr Bull. 2009;36(6):909-18.

8. Mihalopoulos C, McGorry PD, Carter RC. Is phase-specific, communityoriented treatment of early psychosis an economically viable method of improving outcome? Acta Psychiatr Scand. 1999;100(1):47-55. 
9. Breitborde NJ, Woods SW, Srihari VH. Multifamily psychoeducation for first-episode psychosis: A cost-effectiveness analysis. Psychiatr Serv. 2009;60(11):1477-83.

10. Melle I, Larsen TK, Haahr U, Friis S, Johannesen JO, Opjordsmoen S, et al. Prevention of negative symptom psychopathologies in first-episode schizophrenia: two-year effects of reducing the duration of untreated psychosis. Arch Gen Psychiatry. 2008;65(6):634-40.

11. Bertelsen M, Jeppesen P, Petersen L, Thorup A, Ohlenschlaeger J, le Quach $P$, et al. Five-year follow-up of a randomized multicenter trial of intensive early intervention vs standard treatment for patients with a first episode of psychotic illness: The OPUS trial. Arch Gen Psychiatry. 2008;65(7):762-71.

12. Joseph $R$, Birchwood M. The national policy reforms for mental health services and the story of early intervention services in the United Kingdom. J Psychiatry Neurosci. 2005;30(5):362-5.

13. Hughes F, Stavely H, Simpson R, Goldstone S, Pennell K, McGorry P. At the heart of an early psychosis centre: the core components of the 2014 Early Psychosis Prevention and Intervention Centre model for Australian communities. Australas Psychiatry. 2014;22(3):228-34. 1039856214530479

14. Srihari VH, Breitborde NJ, Pollard J, Tek C, Hyman L, Frisman LK, et al. Public-academic partnerships: Early intervention for psychotic disorders in a community mental health center. Psychiatr Serv. 2009;60(11):1426-8.

15. Hardy KV, Moore M, Rose D, Bennett R, Jackson-Lane C, Gause M, et al. Filling the implementation gap: a community-academic partnership approach to early intervention in psychosis. Early Interv Psychiatry. 2011;5(4):366-74.

16. Uzenoff SR, Penn DL, Graham KA, Saade S, Smith BB, Perkins DO. Evaluation of a multi-element treatment center for early psychosis in the United States. Soc Psychiatry Psychiatr Epidemiol. 2012;47(10):1607-15.

17. Srihari VH, Tek C, Kucukgoncu S, Phutane VH, Breitborde NJK, Pollard J, et al. First-episode services for psychotic disorders in the US public sector: A pragmatic randomized controlled trial. Psychiatr Serv. 2015;66:705-12.

18. Breitborde NJK. Developing a university-based early psychosis program: Overview of EPICENTER. Early Interv Psychiatry. 2012;6:18.

19. Breitborde NJK, Durst LS, Mai-Dixon N, Moreno FA. The Early Psychosis Intervention Center: Exploring the mechanisms of change for psychosocial interventions for first-episode psychosis. Early Interv Psychiatry. 2010;4 Suppl 1:56

20. First MB, Spitzer RL, Gibbon M, William JBW. Structured clinical interview for DSM-IV-TR axis I disorders, research version, patient edition (SCID-I/P). New York: Biometrics Research, New York State Psychiatric Institute; 2002.

21. Perkins DO, Leserman J, Jarskog LF, Graham K, Kazmer J, Lieberman JA. Characterizing and dating the onset of symptoms in psychotic illness: the Symptom Onset in Schizophrenia (SOS) inventory. Schizophr Res. 2000;44(1):1-10

22. Wilkinson GS, Robertson GJ. Wide range achievement test (WRAT4). Lutz, FL: PAR, Inc; 2006.

23. Breitborde NJK, Srihari VH, Pollard JM, Addington DN, Woods SW. Mediators and moderators in early intervention research. Early Interv Psychiatry. 2010;4(2):143-52.

24. Kay SR, Fiszbein A, Opler LA. The positive and negative syndrome scale (PANSS) for schizophrenia. Schizophr Bull. 1987;13(2):261-76.

25. Birchwood M, Smith J, Cochrane R, Wetton S, Copestake S. The social functioning scale. The development and validation of a new scale of social adjustment for use in family intervention programmes with schizophrenic patients. Br J Psychiatry Suppl. 1990;157(6):853-9.

26. Nuechterlein KH, Green MF, Kern RS, Baade LE, Barch DM, Cohen JD, et al. The MATRICS consensus cognitive battery, part 1: test selection, reliability, and validity. Am J Psychiatr. 2008;165(2):203-13.

27. Drake R, Mueser K, McHugo G. Clinician rating scales: alcohol Use scale (AUS), drug Use scale (DUS), and substance abuse treatment scale (SATS). In: Sederer LI, Dickey B, editors. Outcomes assessment in clinical practice. Baltimore, MD: Williams \& Wilkins; 1996. p. 113-6.

28. Rosenheck RA, Leslie DL, Sindelar J, Miller EA, Lin H, Stroup TS, et al. Cost-effectiveness of second-generation antipsychotics and perphenazine in a randomized trial of treatment for chronic schizophrenia. Am J Psychiatr. 2006;163(12):2080-9.

29. Emergency room visits and discharges of inpatients with mental disorders (ICD-9-CM codes 290-319) by category of first-listed and all-listed diagnoses and primary pays [http://www.azdhs.gov/plan/hip/for/mental/2012/mental912.xls]

30. Clark RE, Ricketts SK, McHugo GJ. Legal system involvement and costs for persons in treatment for severe mental illness and substance use disorders. Psychiatr Serv. 1999;50(5):641-7.
31. Belfield CR, Levin HM, Rosen R. The economic value of opportunity youth. Washington, D.C.: The Corporation for National and Community Service and The White House Council for Community Solutions; 2012.

32. Phutane VH, Tek C, Chwastiak L, Ratliff JC, Ozyuksel B, Woods SW, et al. Cardiovascular risk in a first-episode psychosis sample: A 'critical period'for prevention? Schizophr Res. 2011;127(1):257-61.

33. Srihari VH, Phutane VH, Ozkan B, Chwastiak L, Ratliff JC, Woods SW, et al. Cardiovascular mortality in schizophrenia: Defining a critical period for prevention. Schizophr Res. 2013;146(1-3):64-8.

34. Leucht S, Samara M, Heres S, Patel MX, Woods SW, Davis JM. Dose equivalents for second-generation antipsychotics: The minimum effective dose method. Schizophr Bull. 2014;40(2):314-26.

35. Woods SW. Chlorpromazine equivalent doses for the newer atypical antipsychotics. J Clin Psychiatry. 2003;64(6):663-7.

36. Occupational Employment Statistics: May 2013 National Occupational Employment and Wage Estimates, United States [http://www.bls.gov/oes/ current/oes_nat.htm\#21-0000]

37. Lehman AF, Steinwachs DM. Patterns of usual care for schizophrenia: initial results from the Schizophrenia Patient Outcomes Research Team (PORT) Client Survey. Schizophr Bull. 1998;24(1):11-20. discussion 20-32.

38. Dixon LB, Dickerson F, Bellack AS, Bennett M, Dickinson D, Goldberg RW, et al. The 2009 schizophrenia PORT psychosocial treatment recommendations and summary statements. Schizophr Bull. 2010;36(1):48-70.

39. West JC, Wilk JE, Olfson M, Rae DS, Marcus S, Narrow WE, et al. Patterns and quality of treatment for patients with schizophrenia in routine psychiatric practice. Psychiatr Serv. 2005;56(3):283-91.

40. Pelosi AJ, Birchwood M. Is early intervention for psychosis a waste of valuable resources? Br J Psychiatry Suppl. 2003;182:196-8.

41. Bosanac P, Patton GC, Castle DJ. Early intervention in psychotic disorders: faith before facts? Psychol Med. 2010;40(3):353-8.

42. Kendall PC, Beidas RS. Smoothing the trail for dissemination of evidencebased practices for youth: Flexibility within fidelity. Prof Psychol: Res Pract. 2007;38(1):13-20.

43. Kendall PC, Gosch E, Furr JM, Sood E. Flexibility within fidelity. J Am Acad Child Adolesc Psychiatry. 2008;47(9):987-93.

44. Zimmermann G, Favrod J, Trieu VH, Pomini V. The effect of cognitive behavioral treatment on the positive symptoms of schizophrenia spectrum disorders: a meta-analysis. Schizophr Res. 2005;77(1):1-9.

45. McFarlane WR. Multifamily groups in the treatment of severe psychiatric disorders. New York: Guilford; 2002.

46. Halperin S, Nathan P, Drummond P, Castle D. A cognitive-behavioural, group-based intervention for social anxiety in schizophrenia. Aust N Z J Psychiatry. 2000;34(5):809-13.

47. Sensky T, Turkington D, Kingdon D, Scott JL, Scott J, Siddle R, et al. A randomized controlled trial of cognitive-behavioral therapy for persistent symptoms in schizophrenia resistant to medication. Arch Gen Psychiatry. 2000;57(2):165-72.

48. Hall PL, Tarrier N. The cognitive-behavioural treatment of low self-esteem in psychotic patients: a pilot study. Behav Res Ther. 2003;41(3):317-32.

49. Lysaker PH, Davis LW, Bryson GJ, Bell MD. Effects of cognitive behavioral therapy on work outcomes in vocational rehabilitation for participants with schizophrenia spectrum disorders. Schizophr Res. 2009;107(2-3):186-91.

50. McGurk SR, Twamley EW, Sitzer DI, McHugo GJ, Mueser KT. A meta-analysis of cognitive remediation in schizophrenia. Am J Psychiatr. 2007;164(12):1791-802.

51. Substance Abuse and Mental Health Services Administration. Supported employment evidence-based practices kit. DHHS Pub. No. SMA-08-4364. Rockville, MD: Center for Mental Health Services, Substance Abuse and Mental Health Service Administration, U.S. Department of Health and Human Services; 2009.

52. Substance Abuse and Mental Health Services Administration. Supported education evidence-based practices kit. DHHS Pub. No. SMA-11-4654. Rockville, MD: Center for Mental Health Services, Substance Abuse and Mental Health Service Administration, U.S. Department of Health and Human Services; 2011.

53. Dickerson FB, Lehman AF. Evidence-based psychotherapy for schizophrenia. J Nerv Ment Dis. 2006;194(1):3-9.

54. Wykes T, Huddy V, Cellard C, McGurk SR, Czobor P. A meta-analysis of cognitive remediation for schizophrenia: methodology and effect sizes. Am J Psychiatr. 2011;168(5):472-85.

55. Saksa JR, Cohen SJ, Srihari VH, Woods SW. Cognitive behavior therapy for early psychosis: A comprehensive review of individual vs. group treatment studies. Int J Group Psychother. 2009;59(3):357-83. 
56. Jauhar S, McKenna P, Radua J, Fung E, Salvador R, Laws K. Cognitive-behavioural therapy for the symptoms of schizophrenia: Systematic review and meta-analysis with examination of potential bias. Br J Psychiatry Suppl. 2014;204(1):20-9.

57. Hagen R, Turkington D, Grawe RW. CBT for psychosis: A symptom-based approach. London: Routledge; 2011.

58. Tarrier N. Schizophrenia and other psychotic disorders. In: Barlow D, editor. Clinical handbook of psychological disorders: a step-by-step treatment manual. New York: Guilford Press; 2007. p. 463-91.

59. Beck AT, Rector NA, Stolar N, Grant P. Schizophrenia: Cognitive theory, research, and therapy. New York: The Guilford Press; 2009.

60. Myers E, Startup H, Freeman D. Improving sleep, improving delusions: CBT for insomnia in individuals with persecutory delusions. In: Steel C, editor. CBT for schizophrenia: evidence-based interventions and future directions. Malden, MA: John Wiley \& Sons; 2013. p. 213-33.

61. Hardy A, Smith B, Gottlieb J, Mueser K, Steel C. CBT for post-traumatic stress disorder and psychosis. In: Steel C, editor. CBT for schizophrenia: evidencebased interventions and future directions. Malden, MA: John Wiley \& Sons; 2013. p. 35-55.

62. Callcott P, Dudley R, Standart S, Freeman M, Turkington D. Treating trauma in people with first-episode psychosis using cognitive behavioural therapy. In: Hagen R, Turkington D, Berge T, Gråwe RW, editors. CBT for psychosis: a symptom-based approach. New York: Routledge/Taylor \& Francis Group; 2011. p. 175-92.

63. Kavanagh DJ, Mueser KT. The treatment of substance misuse in people with serious mental disorders. In: Hagen R, Turkington D, Berge T, Gråwe RW, editors. CBT for psychosis: a symptom-based approach. New York: Routledge/Taylor \& Francis Group; 2011. p. 161-74.

64. Davis LW, Lysaker PH, Lancaster RS, Bryson GJ, Bell MD: The Indianapolis Vocational Intervention Program: A cognitive behavioral approach to addressing rehabilitation issues in schizophrenia. J Rehabil Res Dev. 2005;42(1):35-46.

65. Birchwood M, Trower P: The future of cognitive-behavioural therapy for psychosis: not a quasi-neuroleptic. Brit J Psychiatry. 2006;188(2):107-108.

66. Bell MD, Choi J, Lysaker P. Psychological interventions to improve work outcomes for people with psychiatric disabilities. In: Hagen R, Turkington D, Berge T, Gråwe RW, editors. CBT for psychosis: a symptom-based approach. New York: Routledge/Taylor \& Francis Group; 2011. p. 210-30.

67. Breitborde NJK, Srihari VH: Family work for first-episode psychosis: A service delivery protocol. In: Psychosis: Causes, Diagnosis and Treatment. edn. Edited by Anastassiou-Hadjicharalambous X. Hauppauge, NY: Nova Publishers; 2012. pp. 183-206

68. McFarlane WR, Lukens E, Link B, Dushay R, Deakins SA, Newmark M, et al: Multiple-family groups and psychoeducation in the treatment of schizophrenia. Arch Gen Psychiatry. 1995;52(8):679-87.

69. Browne M, Peer J, Spaulding W: Best practice guidelines for cognitive rehabilitation for people with serious mental illness. Developed for the Behavioral Health Recovery Management Project. An initiative of Fayette Companies, Peoria, IL; Chestnut Health Systems, Bloomington, IN, and the University of Chicago Center for Psychiatric Rehabilitation. http://www.bhrm.org/guidelines/spaulding.pdf.

70. Catalog of clinical training opportunities: Best practices for recovery and improved outcomes for people with serious mental illness [http://www.apa.org/practice/resources/grid/catalog.pdf]

71. Breitborde NJK, Woolverton C, Dawson SC, Bismark AW, Bell EK, Bathgate CJ, et. al. Metacognitive skills training enhances computerized cognitive remediation outcomes among individuals with first-episode psychosis. Early Interv Psychiatry 2015; doi:10.1111/eip.12289.

72. Breitborde NJK, Dawson SC, Woolverton C, Dawley D, Bell EK, Norman K, et al. A randomized controlled trial of cognitive remediation and $d$-cycloserine for individuals with bipolar disorder. BMC Psychol. 2014;2:41.

73. Bracy O. PSSCogRebab, Version 2012. Indianapolis, IN: Psychological Software Services, Inc.; 2012.

74. Kurtz MM, Seltzer JC, Shagan DS, Thime WR, Wexler BE. Computer-assisted cognitive remediation in schizophrenia: What is the active ingredient? Schizophr Res. 2007;89(1):251-60.

75. Greig TC, Zito W, Wexler BE, Fiszdon J, Bell MD. Improved cognitive function in schizophrenia after one year of cognitive training and vocational services. Schizophr Res. 2007;96(1):156-61.

76. Fiszdon J, Choi J, Bryson G, Bell M. Impact of intellectual status on response to cognitive task training in patients with schizophrenia. Schizophr Res. 2006;87(1):261-9.
77. Fiszdon JM, Bryson GJ, Wexler BE, Bell MD. Durability of cognitive remediation training in schizophrenia: performance on two memory tasks at 6-month and 12-month follow-up. Psychiatry Res. 2004;125(1):1-7.

78. Fiszdon JM, Cardenas AS, Bryson GJ, Bell MD. Predictors of remediation success on a trained memory task. J Nerv Ment Dis. 2005;193(9):602-8.

79. Bell M, Bryson G, Greig T, Corcoran C, Wexler BE. Neurocognitive enhancement therapy with work therapy: effects on neuropsychological test performance. Arch Gen Psychiatry. 2001;58(8):763-8.

80. Hogarty GE, Flesher S, Ulrich R, Carter M, Greenwald D, Pogue-Geile M, et al. Cognitive enhancement therapy for schizophrenia: Effects of a 2-year randomized trial on cognition and behavior. Arch Gen Psychiatry. 2004;61(9):866-76.

81. Breitborde NJ, Moreno FA, Mai-Dixon N, Peterson R, Durst L, Bernstein B, et al. Multifamily group psychoeducation and cognitive remediation for first-episode psychosis: A randomized controlled trial. BMC Psychiatry. 2011;11:9.

82. Montori VM, Guyatt GH. Intention-to-treat principle. Can Med Assoc J. 2001;165(10):1339-41.

83. Graham JW. Missing data analysis: making it work in the real world. Annu Rev Psychol. 2009;60:549-76.

84. Palmer RF, Royall DR. Missing data? plan on it! J Am Geriatr Soc. 2010;58 Suppl 2:S343-8.

85. Royston P. Multiple imputation of missing values: update of ice. STATA J. 2005;5(4):527-36.

86. Rubin DB. Multiple imputation for non-response in surveys. New York: John Wiley \& Sons; 1987.

87. Marshall A, Altman DG, Holder RL, Royston P. Combining estimates of interest in prognostic modelling studies after multiple imputation: Current practice and guidelines. BMC Med Res Methodol. 2009;9:57.

88. Barnard J, Rubin DB. Miscellanea. Small-sample degrees of freedom with multiple imputation. Biometrika. 1999;86(4):948-55.

89. Gray BE, McMahon RP, Green MF, Seidman LJ, Mesholam-Gately Rl, Kern RS, et al. Detecting reliable cognitive change in individual patients with the MATRICS Consensus Cognitive Battery. Schizophr Res. 2014;159(1):182-7.

90. Liu X, De Haan S. Chlorpromazine dose for people with schizophrenia. Cochrane Database Syst Rev. 2009;15(2):CD007778. Art. No.

91. Goldstein MJ. Psycho-education and family treatment related to the phase of a psychotic disorder. Int Clin Psychopharmacol. 1996;11 Suppl 2:77-83.

92. Harvey P, Lepage M, Malla A. Benefits of enriched intervention compared with standard care for patients with recent-onset psychosis: a metaanalytic approach. Can J Psychiatr. 2007;52(7):464.

93. Wyatt RJ, Henter I, Leary MC, Taylor E. An economic evaluation of schizophrenia-1991. Soc Psychiatry Psychiatr Epidemiol. 1995;30(5):196-205.

94. Rice DP, Miller LS. The economic burden of schizophrenia: Conceptual and methodological issues and cost estimates. In: Moscarelli M, Rupp A, Sartorius N, editors. Handbook of mental health economics and health policy. Volume 1: Schizophrenia, edn. New York, NY: John Wiley \& Sons; 1996.

95. Leucht S, Cipriani A, Spineli L, Mavridis D, Örey D, Richter F, et al. Comparative efficacy and tolerability of 15 antipsychotic drugs in schizophrenia: a multipletreatments meta-analysis. Lancet. 2013;382(9896):951-62.

96. Verdoux H, Lengronne J, Liraud F, Gonzales B, Assens F, Abalan F, et al. Medication adherence in psychosis: Predictors and impact on outcome. A 2-year follow-up of first-admitted subjects. Acta Psychiatr Scand. 2000;102(3):203-10.

97. International First Episode Vocational Recovery Group. Meaningful lives: Supporting young people with psychosis in education, training and employment: an international consensus statement. Early Interv Psychiatry. 2010;4(4):323.

98. Lewandowski K, Cohen B, Öngur D. Evolution of neuropsychological dysfunction during the course of schizophrenia and bipolar disorder. Psychol Med. 2011:41(02):225-41.

99. Mesholam-Gately RI, Giuliano AJ, Goff KP, Faraone SV, Seidman L. Neurocognition in first-episode schizophrenia: a meta-analytic review. Neuropsychology. 2009;23(3):315.

100. Addington J, Penn D, Woods SW, Addington D, Perkins DO. Social functioning in individuals at clinical high risk for psychosis. Schizophr Res. 2008;99(1):119-24. 